\title{
Suprachoroidal Route of Administration
}

National Cancer Institute

\section{Source}

National Cancer Institute. Suprachoroidal Route of Administration. NCI Thesaurus. Code C128997.

Administration above the choroid. 